\title{
StEMORS: A Stochastic Eco-Hydrological Model for Optimal Reservoir Sizing
}

\author{
Aristotelis Koskinas ${ }^{1}$, Pinelopi Tsira ${ }^{2}$ and Aristoteles Tegos ${ }^{3}$ \\ 1 AECOM, $4^{\text {th }}$ Floor, Adelphi Plaza, George's Street Upper, Dun Laoghaire, Dublin A96 T927, Ireland; \\ telis.koskinas@aecom.com \\ 2 Independent researcher - Civil Engineer, 3 Tranquilla Mews, Hillside Road, Greystones, Co. \\ Wicklow, Ireland; tsira_p@hotmail.com \\ 3 Department of Water Resources and Environmental Engineering, National Technical University of \\ Athens, Heroon Polytechniou 9, Zografou, GR-15780 Zografou Athens, Greece; tegosaris@yahoo.gr
}

\begin{abstract}
Dams design and their operation cause strong environmental alteration and therefore a long-term debate is ongoing for the scale of these projects. At the same time, the concept of Environmental Flow Assessment (EFA) is a crucial element of modified ecosystems featuring large infrastructure such as dams and reservoirs for mitigating potential environmental degradation while they operate. Nowadays, integrated scientific frameworks are required to quantify the risks caused by large infrastructure. Through the use of stochastic analysis, it is possible to quantify these uncertainties, and present a solution that incorporates long-term persistence and environmental sustainability into a balanced reservoir simulation model. In this work, an attempt is made to determine a benchmark reservoir size incorporating hydrological and ecological criteria though stochastic analysis. The primary goal is to ensure the best possible conditions for the ecosystem, and then secondarily to allow a steady supply of water for other uses. Using a synthetic timeseries based on historical inputs, it is possible to determine and preserve essential statistical characteristics of a river's streamflow, and use these to detect the optimal reservoir capacity that maximizes environmental and local water demand reliability.
\end{abstract}

Keywords: environmental flow assessment; water balance model; stochastic analysis; reliability; dynamic flow regime

\section{Introduction}

Human interventions in the world's aquatic systems due to a constant demand for reliable sources of clean water lead to reasonable concerns over potential impacts on the ecosystems that are affected [1-3]. Large scale human made infrastructure such as dams and associated hydropower facilities, irrigation systems, water supply and wastewater pipe networks, water and wastewater treatment plants all play an important part in the continuous advancement of civilization. Yet, mainly due to their scale, these works cause significant alterations to the environment. The engineering problem of adapting the local area to suit human needs has led to advancements in technology and scientific knowledge from ancient times $[4,5]$ until nowadays [6]. Sustainability and safety have always been primary drivers for these works, with the aim of balancing the scale of human alterations to avoid heavily disrupting local ecosystems. One of these engineering areas, dam design, is still receiving strong criticism from the scientific community for its harmful effects on the natural environment $[2,7,8]$. The main issues documented are the massive landscaping works required which dramatically change a natural ecosystem, followed by direct impacts such as decrease or rapid changes in biotic and abiotic populations $[9,10]$. 
In order to help preserve key valuable aspects of riverine ecosystems, several factors come into play. The first one that comes to mind is the river's streamflow itself, as it can be clearly defined and measured in terms of quantity and quality. Therefore, an environmental flow scheme is one of the most suggested methods of maintaining original conditions in any damimpacted stream $[6,11,12]$. Simply put, it is a scheme put into place that can regulate the outflows from dams, in a way that can protect or even bolster the living conditions of riverine wildlife. The core concept is that at the very least, a minimum amount of water should be running through a river at all times to sustain local animal populations. One must not be mistaken at this point to believe that maintaining a certain downstream flow quantity is the definitive solution to the problem. Many ecosystems require a very unstable flow scheme for an ideal replica of original conditions, including frequent floods or long periods of drought $[13,14]$. At this point, human intervention is a double-edged sword; by introducing a regulated flow schedule, it could be unclear whether an ecosystem benefits or is damaged. As a measure of quantifying this impact, researchers have combined the efforts of multiple fields of study, including biology, physics, geology, and chemistry in an attempt to break down an ecosystem into components that can be assessed individually at first, then combined and evaluated overall [10,15-17].

This overall combination of elements could also be referred to as ecosystem balance. On the one hand, a typical river habitat is mainly comprised of a streamflow regime and its water quality, its wildlife composition and subsequent biological interactions, as well as geomorphological factors such as river hydraulics, soil materials, connectivity between streams and presence of physical barriers or a lack thereof [18-20]. On the other hand, human activities may disturb this balance by modifying a river's flow, the quality of its water or the shape of its channel, fishing, or introducing new species. On a larger scale, landscaping works required for larger water infrastructure such as a dam may cause major alterations, to the point where the nature of this balance changes entirely into a new ecosystem. The primary reason for this is to avail of local resources, mostly water, to cover human needs. It is the nature of these changes that must be weighed against their impacts on a river catchment's natural conditions $[9,21,22]$.

Once again, adequately quantifying these effects is a daunting prospect for researchers, as oftentimes the effects of human intervention in riverine ecosystems are beneficial or adverse depending on reasons more subjective than objective, and it can be very unclear what changes should be classified as either. Socioeconomic factors also come into play here - for example, a local community in dire need of water may be a lot more willing to accept major changes to the original landscape, at the expense of natural wildlife, in order to sustain their needs [23-25]. In any case, researchers have outlined some indicative components of environmental flow in an effort to cover the needs of the people while balancing these against mitigating damages to natural habitats. Legislation implemented in various countries around the world usually suggests that dam operators implement some type of base flow policy. In broad terms, this often refers to a ensuring a certain outflow, calculated as a percentage of mean annual flow. For example, in Europe countries usually employ schemes that require that flow below dams be at least $5 \%$ of mean annual flow (Portugal) or at least minimum average monthly flow (Greece). In the UK, the minimum is the $Q_{95}$ percentile, as in the flow that is exceeded $95 \%$ of the time in a given stream. This method is a lot more versatile when it comes to countries with multiple types of ecosystems, which is why it also has been adopted broadly in Australia, and in a similar vein, countries like Canada and Brazil apply a stricter $Q_{90}$ discharge. Furthermore, the UK standard has recently taken center stage as it is now also employed by the European Water Framework Directive (WFD), which imposes $Q_{95}$ as a bare minimum flow, while simultaneously applying further restrictions such as abstraction thresholds in excess of this flow to preserve local fish populations [26-28].

More recently, these concepts have been expanded upon, eventually leading to Environmental Flow Assessment, or EFA. The core values of EFAs go beyond protecting the 
already mentioned minimum value of flow in an impacted river, now incorporating multiple physical aspects of a catchment, such as floodplains, groundwater, downstream conditions, as well as expanding highly into the nature of streamflow, including complex variables such as flow duration, timing, and rate of change $[19,29,30]$. While EFA as an idea already exists in reports dating as far back as 1940s California [31], more recently numerous methods have appeared in the field, each adapting to the various available inputs and required outputs. Today, EFAs now include complex models of instream flows, fish flows and even artificial flooding [28].

Recently, in countries such as the UK, Australia and South Africa, a holistic EFA approach known as the Downstream Response to Imposed Flow Transformations (DRIFT) has been applied in various water resources projects [17]. Key benefits of this framework are its interactivity, allowing researchers to provide multiple data-driven flow scenarios, allowing stakeholders to compare and contrast according to whatever water uses need to be met. It is comprised of four components or modules: biophysical, sociological, scenario development and economic. The first requires a description of riverine ecosystem components. For example, a breakdown of the local fish population would require information such as habitat use, movement, and water quality tolerances for reproduction. Next, the sociological component identifies local residents who are classified as "at-risk", attempts to develop predictions of future changes to the landscape and their likely consequences. In the scenario development phase, the possible future flow schemes and biophysical aspects are detailed in discrete outputs, and in the final economic module, compensation costs for the people at risk are calculated and included in the final outputs to be presented for assessment. This framework has recently been applied in the small South African country of Lesotho as part of the Lesotho Highlands Water Project (LHWP) [30,32].

The aim of this study is, while relying on tried and tested EFA methods, to distill the above concepts into a simplified "benchmark" model, combining a hydrological and ecological engineering viewpoint into reservoir design. This "eco-hydrological" aspect intends to maintain sustainability as the primary parameter, while also presenting the ability to include clearly defined and quantifiable inputs, leading to equally clear outputs which can be of use to dam engineers looking to determine optimal sizes for their dam reservoirs. Uncertainty in flow assessment is a key factor at this point, and quantifying it is best achieved through stochastic analysis. While this article focuses on a single case study in Lesotho, the goal is to present a model that can be applied in any dam engineering design, once the necessary hydrological and environmental criteria have been studied and included. 


\section{Study Area}

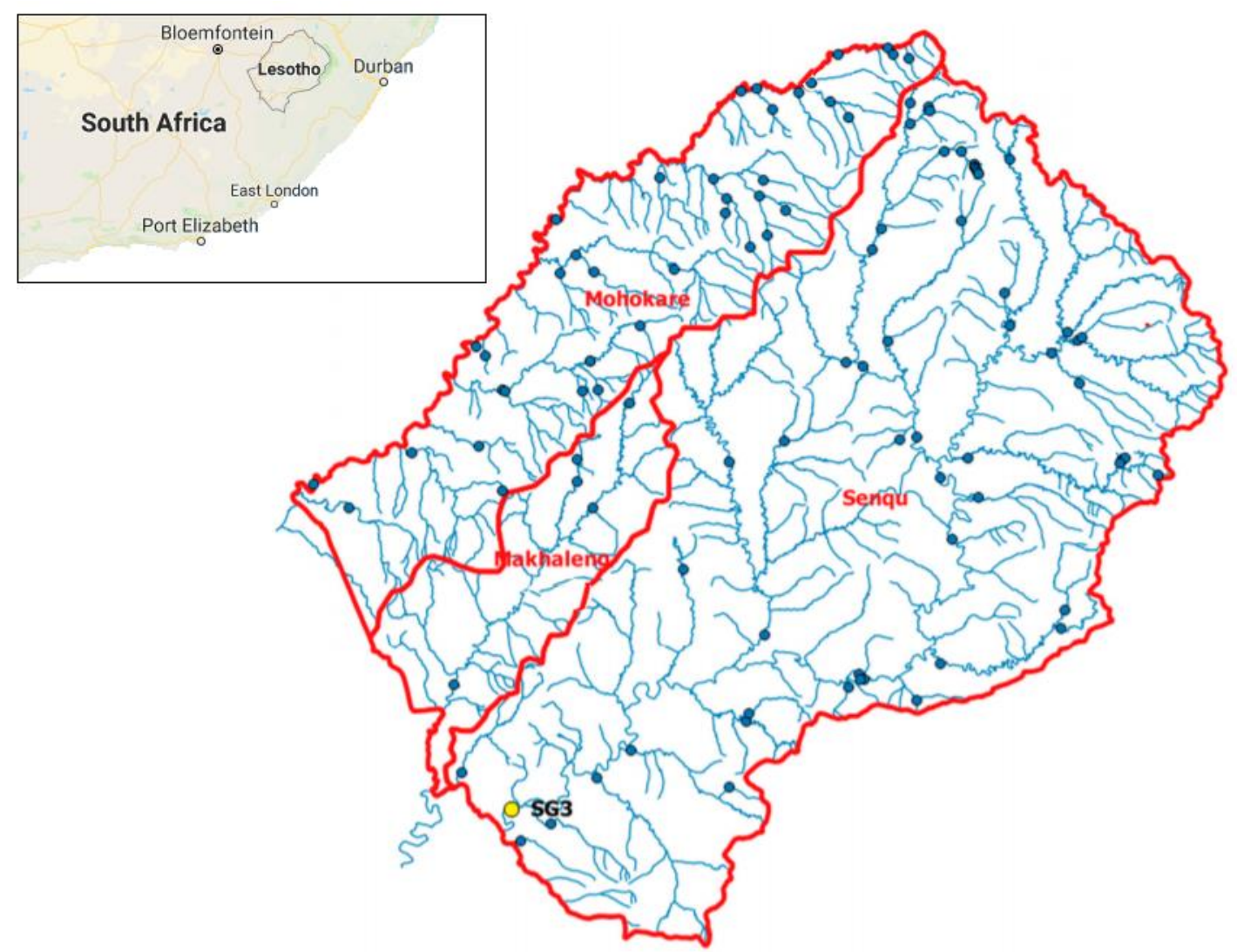

Figure 1. Map of Lesotho. Lesotho's catchment boundaries are shown in red, hydrographic network in blue, flow monitoring stations are the blue dots, and the pertinent hydrometric station SG3 (highlighted in yellow) [28].

This study focuses on the Kingdom of Lesotho. It is a small country, with a primarily mountainous geomorphology, located entirely within South Africa. Its largest river, Senqu in the east, is one of three major rivers that contain most of the country's surface water, the other being Mohokare in the west and Makhaleng in the central regions.

The climate in Lesotho is generally characterized by cool, dry winters and a hot, humid summer season. Precipitation ranges between 500 and $1200 \mathrm{~mm}$ on average, with almost $85 \%$ of total precipitation occurring between October and April. Furthermore, it seems to be influenced mainly by elevation and orientation of rainfall. For the southeastern part of the country, the influence of topography on data has been documented in various studies $[23,33,34]$. In general, there appear to be three distinct zones; one in the center of the Lesotho highlands containing parts of low rainfall rainshadow, one comprised of smaller areas around the former, and finally, a zone made of areas along the country's southeastern border. Here, the slopes face primarily eastward, and the altitude is predominantly high. A comprehensive map of mean total annual precipitation of various smaller catchment areas in the southeastern part of Lesotho is available in Figure 3 below. 


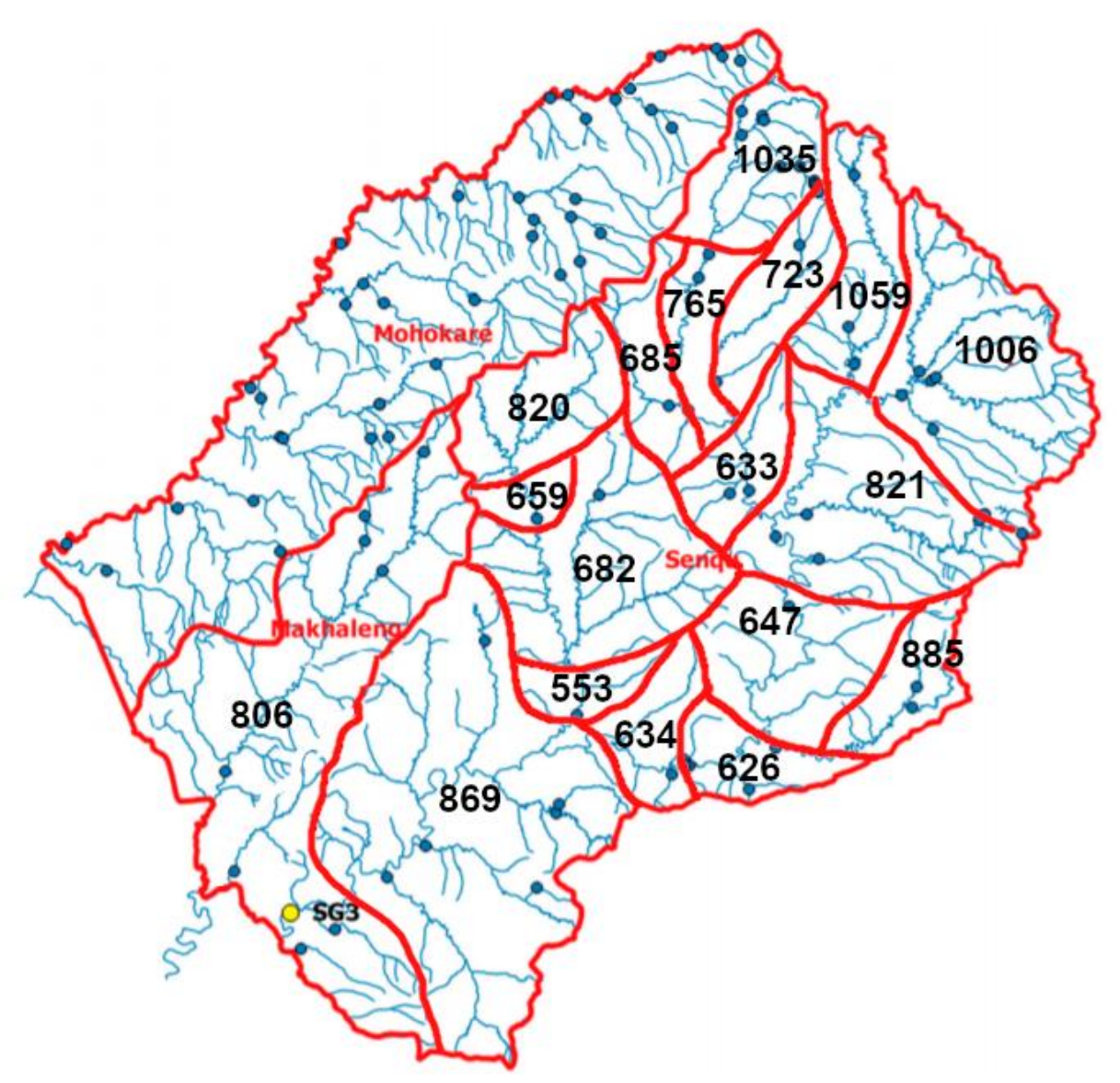

Figure 2. Estimated mean annual precipitation (mm) for the years 1975-1990 per flow gauge catchment [33].

On the relationship between rainfall and flow, it is important to gather information on the annual values of each for a stochastic model. The geomorphology of the country helps promote a strong correlation between the two, as it is mostly comprised of thin soils and basaltic rock, leading to low permeability and high runoff coefficients. This factor combined with frequent dry seasons means very little water carries over between hydrological years.

It is these lengthy dry periods that spark the need for the Lesotho Highlands Water Project (LHWP). This encompasses the building of several dams in the region, allowing for water storage and export to South Africa, as well as generating electricity. When complete, this project could account for $20 \%$ of the country's total income [32,34]. Environmental flow downstream of existing and planned dams is a key element for this project, and most studies in the region so far rely on various applications of the popular DRIFT framework, which uses hydraulic data as well as ecological information such as fish surveys [17,35].

69 operational river flow monitoring stations currently are available across the three rivers mentioned above, but the data analyzed in the study is acquired from station SG3, Senqu River at Seaka Bridge. This measurement station returns daily streamflow in cubic meters per second. After aggregating these inputs into monthly data, it is possible to create a timeseries starting from the hydrological year 1972-73 until 1993-94. This particular time period is selected, as after this point in time the river's flow begins to be impacted by human projects. As unregulated flow data is required for this research, only these historical values are retained as they are more likely to be accurate. By regulating more recent flows using a mathematical method, there is a risk of errors in later calculations $[14,28,30,35]$. The aggregated timeseries is shown in Figure 3 below. 


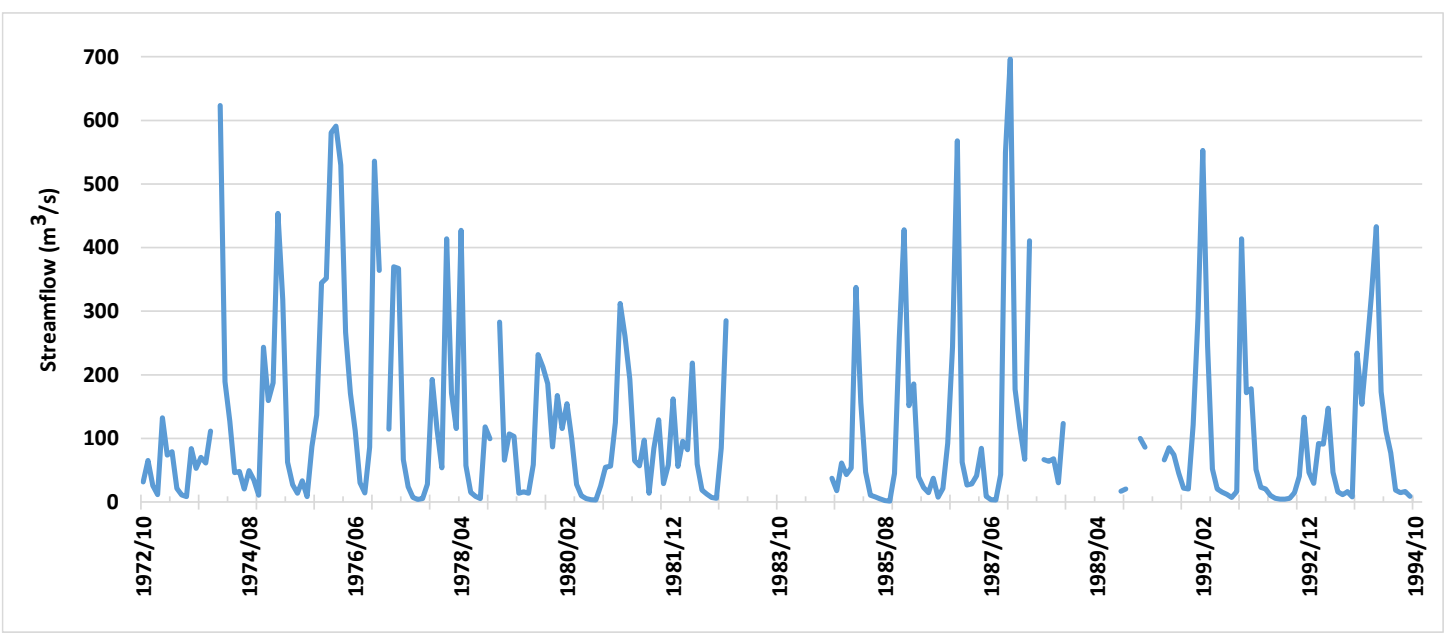

Figure 3. Monthly streamflow at station SG3, Senqu River at Seaka Bridge, between hydrological years 1972-73 and 1993-94. $\left(\mathrm{m}^{3} / \mathrm{s}\right)$.

Regarding the aggregation method, it is important to note that several months have missing daily data and are therefore disregarded. In general, a month is not included in the data if there aren't at least 25 daily measurements per month (corresponding to less than one missing day per week.) For the remaining months, they are flagged as "missing" if they lack at least one daily measurement. In the data kept for further calculations, there is at least one missing day in only $18.94 \%$ of months, and these are considered accurate enough based on similar studies in the same area. Also of note, for the selected data, the average monthly value

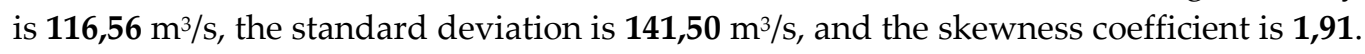

\section{Materials and Methods}

It is common knowledge [36] that for any autocovariance sequence $\gamma_{j}$, the weighted sum $X_{t}$ of of an infinite series of values of a white noise variable $V_{i}$ can be described in the following form (also known as a backward moving average (BMA) model):

$$
X_{t}=\sum_{j=-\infty}^{0} \alpha_{-j} V_{i+j}=\cdots+\alpha_{2} V_{i-2}+\alpha_{1} V_{i-1}+\alpha_{i} V_{0}
$$

where $\alpha_{j}$ are numerical coefficients, determined from the sequence $\gamma_{j}$ as denoted below:

$$
\sum_{j=0}^{\infty} \alpha_{j} a_{i+j}=\gamma_{i} \quad i=0,1,2, \cdots
$$

By expanding upon this original idea, it is possible to describe this sum in a backwardforward moving average (BFMA) form:

$$
X_{t}=\sum_{j=-\infty}^{0} \alpha_{-j} V_{i+j}=\cdots+\alpha_{2} V_{i-2}+\alpha_{1} V_{i-1}+\alpha_{i} V_{0}
$$

where now, the numerical coefficients $\alpha_{\mathrm{j}}$ change to the following:

$$
\sum_{j=-\infty}^{\infty} \alpha_{j} a_{i+j}=\gamma_{i} \quad i=0,1,2, \cdots, n .
$$

The main benefit of the BFMA model (3) is its flexibility, since the number of parameters $\alpha_{\mathrm{j}}$ is double that of model (1). One special case of (3) is that with 


$$
a_{j}=a_{-j} \quad j=1,2, \cdots
$$

This special case is referred to as the Symmetric Moving Average (SMA) model [37], and the weighted sum $X_{t}$ is described now as below:

$$
X_{t}=\sum_{j=-s}^{s} \alpha_{|j|} V_{i+j}=\alpha_{s} V_{i-s}+\cdots+\alpha_{1} V_{i-1}+\alpha_{0} V_{i}+\alpha_{1} V_{i+1}+\cdots+\alpha_{s} V_{i+s}
$$

The number of white noise variables is now set to a finite number $s$, chosen depending to the desired accuracy one wishes to achieve, assuming that $\alpha_{j}=0$ for $|\mathrm{j}|>s$. Also, the $\alpha_{\mathrm{j}}$ coefficients now become

$$
\sum_{j=-s}^{s-1} \alpha_{|j|} a_{|i+j|}=\gamma_{i} \quad i=0,1,2, \cdots
$$

In this study, a simple reliability-based reservoir model test is proposed, similar to the concept described in a study by Koutsoyiannis, but now incorporating a dynamic environmental flow regime [28,38]. This involves a simple water balance equation, formulated as

$$
S t=\max \left[0, \min \left(S_{t-1}+X_{t}-\delta t, c\right)\right]
$$

where $S_{t}$ is water volume stored at time $t$, above the minimum level, $X_{t}$ denotes inflow at time $t, \delta t$ is total water demand for the time period of $(t-1, t)$, and $c$ is the reservoir storage volume assumed. Furthermore, to estimate reliability $a$, the following formula is required:

$$
a=\frac{1}{n} \sum_{t=1}^{n}[1-U(-S t)]
$$

where $U(x)$ is the Heaviside's unit step function, assuming $U(x)=1$ for $x \geq 0$ and $U(x)=0$ for $x<0$. The variable $n$ represents the length of the timeseries. Then, storage is stanardized as a non-dimensional net storage capacity $K^{*}$, described as follows:

$$
K^{*}=\frac{c-\mu}{\sigma}
$$

where $c$ is the assumed storage, $\mu$ is the mean of annual net inflows $X_{t}$, and $\sigma$ their standard deviation. The aim here is to be able to compare the relationships governing reliability and storage between different case studies [38]. The reservoir model algorithm is described below:

1. Generate a series of inflows $X_{t}$ at a monthly timescale using a stochastic algorithm.

2. Assume a reservoir size $c$.

3. Calculate a series of reservoir storages using (8).

4. Estimate reliability for Environmental Flow and Demand by using (9).

5. Repeat steps 3-4 for different reservoir sizes.

6. Choose the optimum reservoir size by balancing reliability for both ecosystem and demand criteria.

To fulfill step 1, in this study a 1000-year synthetic monthly timeseries is created by implementing the SMA algorithm [37-40]. This can be quickly done by using the Castalia software package [41]. This algorithm is ideal for variables that exhibit periodicity and longterm persistence such as streamflow, and the algorithm preserves key statistics including mean value, standard deviation, and skewness in the generated synthetic timeseries. Next, from this initial output, the overall average is assumed to represent the maximum monthly demand for human needs. Usually, the monthly water requirements are a fraction of this assumed maximum per month. While existing research can justify a reasonably conservative water 
demand estimate, the ideal way of conducting this step would be to obtain exact demand values by conducting surveys and collecting historical data [38,39,42].

To gather information on the environmental flow need of the area, many applications of DRIFT framework in a holistic approach would be suitable, as it has been tried and tested in Lesotho with verifiable accuracy $[17,19,35]$. In the hydrological component of a study conducted by Tegos et al. [28], minimum, median and maximum baseflows, as well as subsistence flows for the river Senqu have been estimated using local data. More specifically, by using the minimum and mean monthly flows as borders, the seasonally varying target flows mentioned above. Subsistence flow was selected as the $Q_{97}$ value (flows that are exceeded $97 \%$ of the time), whereas baseflows were set to $Q_{60}, Q_{75}$, and $Q_{90}$ for minimum, median, and maximum baseflow respectively. All of the above flows are naturalized, so if the reservoir model can accommodate them, the environmental criteria are considered to be met, with reasonable accuracy. Tables 1 and 2 below summarize these values per month.

Table 1. Environmental flow values at SG3 station ( $\left.\mathrm{m}^{3} / \mathrm{s}\right)$, January to June (1972-2011).

\begin{tabular}{ccccccc}
\hline & 1.January & 2.February & 3.March & 4.April & 5.May & 6.June \\
\hline $\begin{array}{c}\text { Max } \\
\text { baseflow }\end{array}$ & 47,21 & 121,35 & 85,16 & 45,17 & 21,26 & 14,27 \\
$\begin{array}{c}\text { Median } \\
\text { baseflow } \\
\begin{array}{c}\text { Proposed } \\
\text { min baseflow }\end{array}\end{array}$ & 27,2 & 30,44 & 29,61 & 30,44 & 24,14 & 25,65 \\
$\begin{array}{c}\text { Subsistence } \\
\text { flow }\end{array}$ & 17,28 & 27,2 & 28,8 & 12,06 & 7,77 & 4,73 \\
\hline
\end{tabular}

Table 2. Environmental flow values at SG3 station (m³/s), July to December (1972-2011).

\begin{tabular}{ccccccc}
\hline & 7.July & 8.August & 9.September & $\begin{array}{c}\text { 10.Octo } \\
\text { ber }\end{array}$ & $\begin{array}{c}\text { 11.Novem } \\
\text { ber }\end{array}$ & $\begin{array}{c}\text { 12.Decem } \\
\text { ber }\end{array}$ \\
\hline $\begin{array}{c}\text { Max } \\
\text { baseflow } \\
\text { Median }\end{array}$ & 9,1 & 6,94 & 12,6 & 28,8 & 62,73 & 70,04 \\
baseflow & 23,4 & 21,26 & 19,89 & 19,89 & 27,2 & 24,29 \\
$\begin{array}{c}\text { Proposed } \\
\text { min baseflow } \\
\begin{array}{c}\text { Subsistence } \\
\text { flow }\end{array}\end{array}$ & 3,78 & 2,75 & 2,75 & 4,73 & 12,6 & 22,68 \\
\hline
\end{tabular}

Now, based off of the available demand data, Step 3 of the reservoir model can be conducted. To achieve this, it is assumed that a normal random value between the minimum and maximum baseflow is drawn from the reservoir for any given month, together with a constant value of water demand for human needs. The latter is represented as a percentage of the assumed maximum and varies per month. Naturally, this demand is low during traditionally wet months in this area, yet reaches $100 \%$ in the peak of the dry season. The goal of calculating a combined demand profile in this way, is to stress test the reservoir model under the primary directive of sustaining a dynamic environmental flow scheme, as current EFA standards require. In this sense, as the priority is to maintain ecosystem balance, a rule is added to the model that environmental flow must be accommodated first, and then human needs. It is easy to quantify the efficiency of meeting both goals by measuring whether they were met or not as a percentage of all months. If a selected environmental flow cannot be accommodated 
for a given month, subsistence flow outflows as an alternative, and if even this is still not possible, whatever remains in the reservoir will outflow instead. Naturally, any excess inflows that are over the preselected dedicated storage $c$ "spill" downstream and are not included into the following month's calculations.

Moving on to the estimation of reliability $a$ for environmental flow and human water demand, it is important to clarify what the model perceives as criteria of success for meeting its preset goals. In this model, if even subsistence flow successfully outflows from the reservoir for a given month, that month is calculated as successful for the model, and fails only if this basic criterion is not met. On the other hand, if the constant monthly value for human water demand cannot be output from the reservoir, the model automatically fails with no backup value. It is relevant to note at this stage that these specific criteria have been selected due to the unique nature of the case study and model goals. As stated previously, the aim for this particular study is to maximize environmental flow reliability at all costs. At the same time, Lesotho is a characteristically dry country [33], therefore it can be assumed that any lengthy period of drought is an environmental "failure". This may not be accurate on a global scale, though; there are case studies around the world where long dry periods can actively benefit the ecosystem $[15,43]$. If the study were to be undertaken in these locations with the same criteria, the model would display a failure in environmental flow reliability, which might then be wrongly mistaken as an overall damage to the ecosystem. Therefore, it is important to understand the model's limitations and tweak it accordingly before applying it in a given location.

\section{Results}

With all of the necessary inputs collected, the reservoir model algorithm detailed above can be implemented for a thousand synthetic years. Figures 4 and 5 below compare standardized reservoir capacity $K^{*}$ with demand and environmental flow reliability.

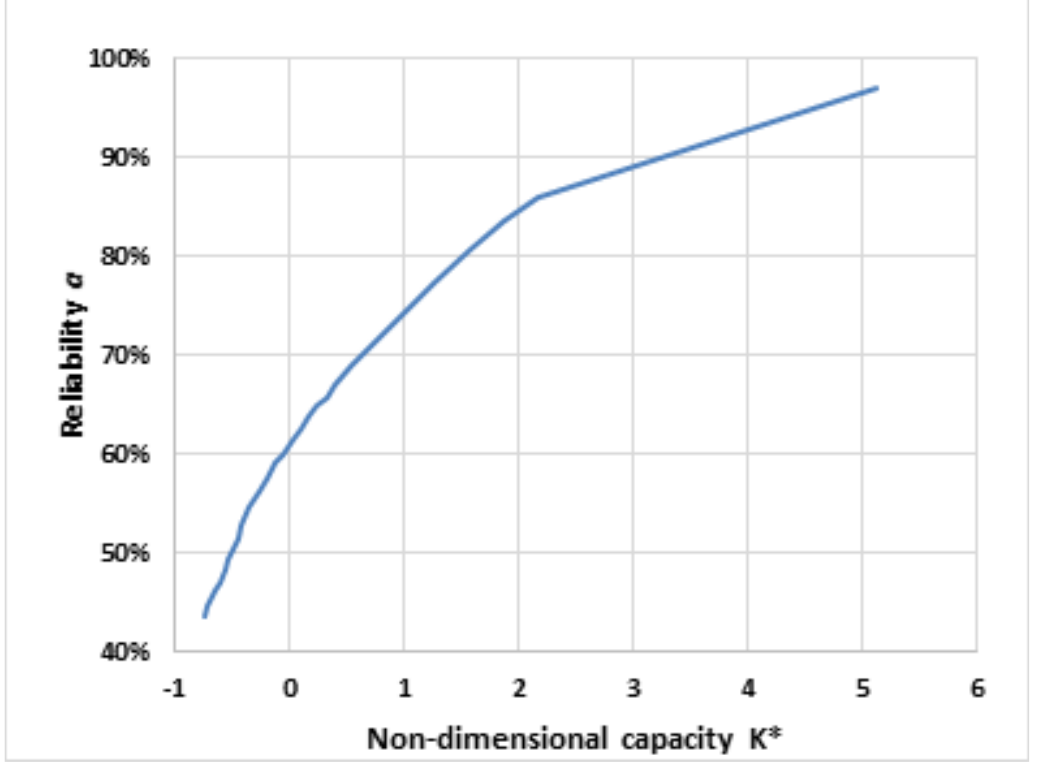

Figure 4. Capacity - demand reliability curve, assuming maximum demand (mean annual inflow is the highest demand value). 


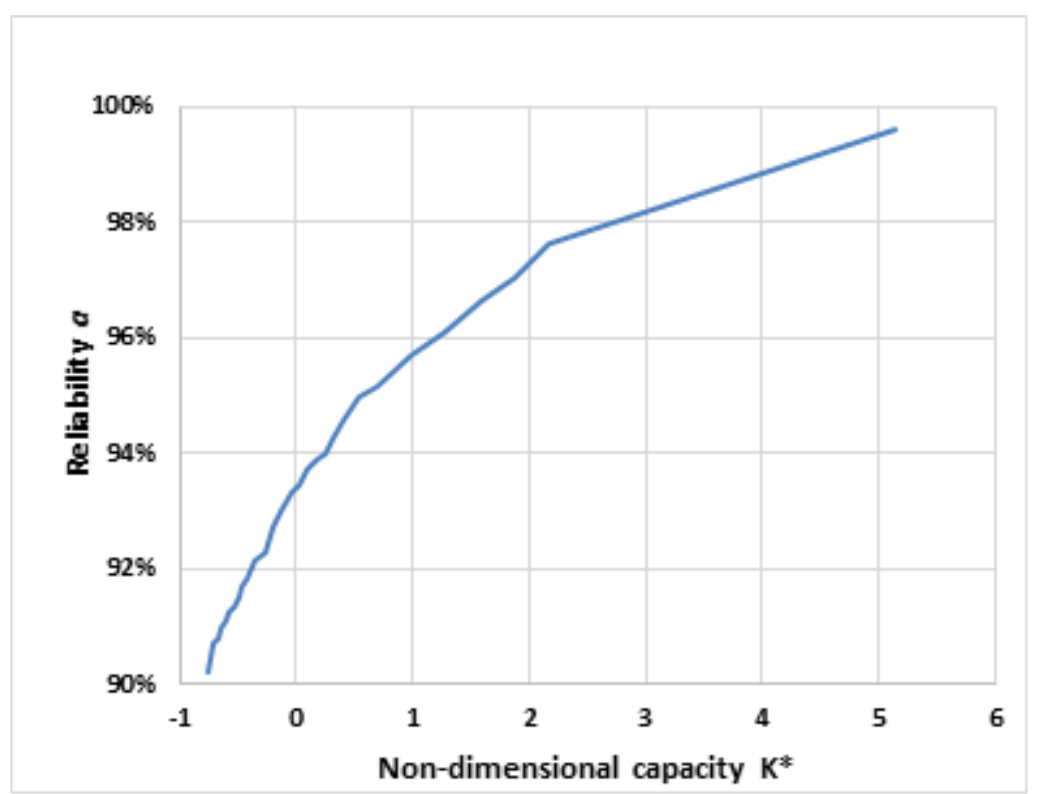

Figure 5. Capacity - environmental flow reliability curve, assuming maximum demand (mean annual inflow is the highest demand value).

As expected, the model can meet enviromental flow requirements much more easily than human demand. This is primarily due to the fact that the former are set as the prime directive, and any water will cover those needs first. Even when setting a very low initial value for reservoir capacity $c$, environmental flow reliability is approximately $90 \%$, while human water demand reliability is $44 \%$. This indicates that even a small reservoir can assist an ecosystem in maintaining at least a basic subistence flow to preserve the bare minimum environmental requirements, immediately offering more options to regulate the river and ensure ecosystem sustainability. When assuming a typical reservoir size $\mathrm{K}^{*}=-0.5$ (For the Lesotho example, corresponding to $1,261 \mathrm{hm}^{3}$ ), environmental flow reliability is now $92 \%$ on average, whereas demand reliability is set to $51 \%$ on average. Evidently, the presence of a small reservoir here has assisted in meeting both demand criteria, but by a rather insignificant amount. The months where reliability is not met here are likely due to extended periods of drought. Manmade reservoirs could prevent this and allow a steadier flow throughout the year even in unfavorable conditions [1]. This point is further shown when a larger reservoir $\mathrm{K}^{*}=0$ is selected (for this area, corresponding to $3,516 \mathrm{hm}^{3}$ ), and these values rise to $93 \%$ and $60 \%$ respectively. While within a theoretical model the storage value can be eventually raised until $100 \%$ reliability overall, in practical terms the possible maximum size is limited. Based on Figures 4 and 5, the most cost-efficient volume for the reservoir appears to be for $K^{*}$ values of 1.5 to 2 . (9,500 to $12,000 \mathrm{hm}^{3}$ storage for the Lesotho example). In any case, this indicates that large reservoirs in general perform better both to facilitate human water needs as well as to output a dynamic ecofriendly flow regime. That said, it is also evident that quickly reservoir sizes become impractically large to build. Lesotho as a case study has the benfit of being mountainous, but in flatter areas a reservoir of this size may be entirely unfeasible. [2,7,44-46].

It it also appropriate to visualise the model's response to demand on a monthly basis for the entire simulation length. Figures 6 and 7 below compare overall reliability per month, assuming $K^{*}=0$. 


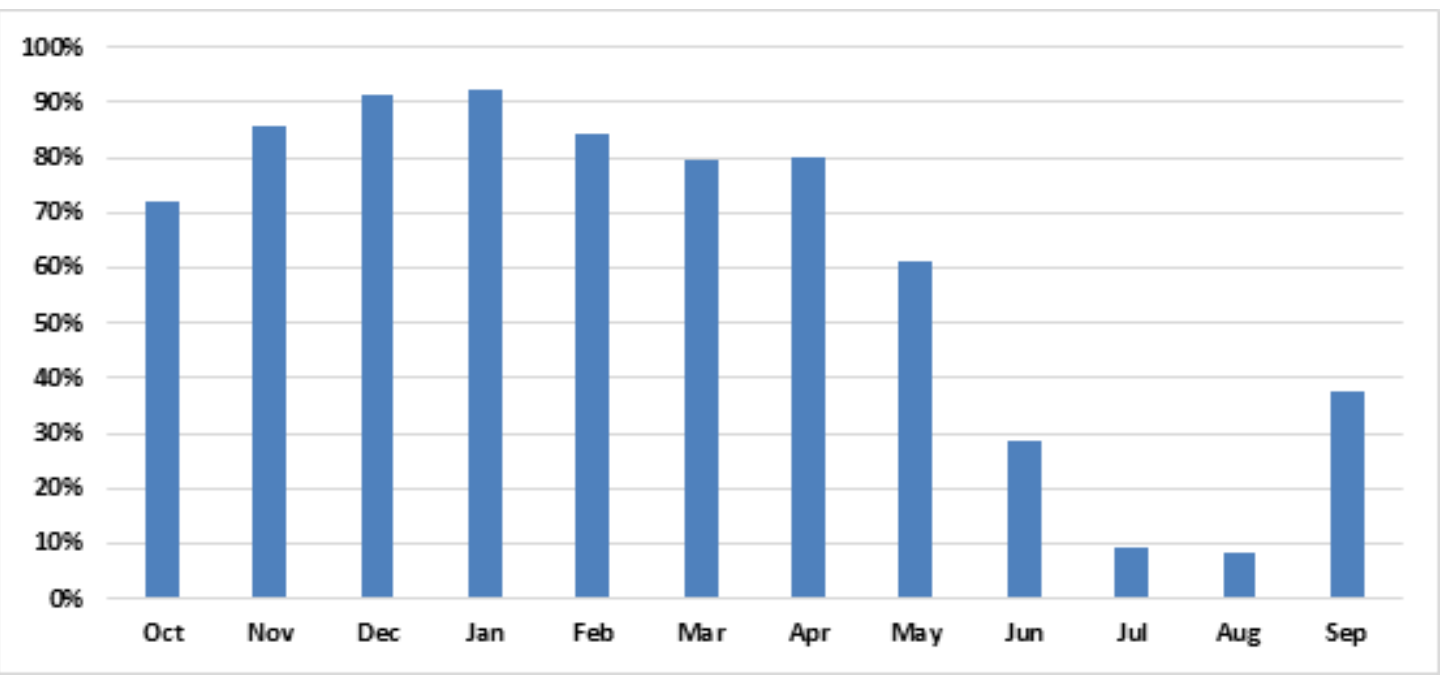

Figure 6. Demand reliability per month, assuming $K^{*}=0$.

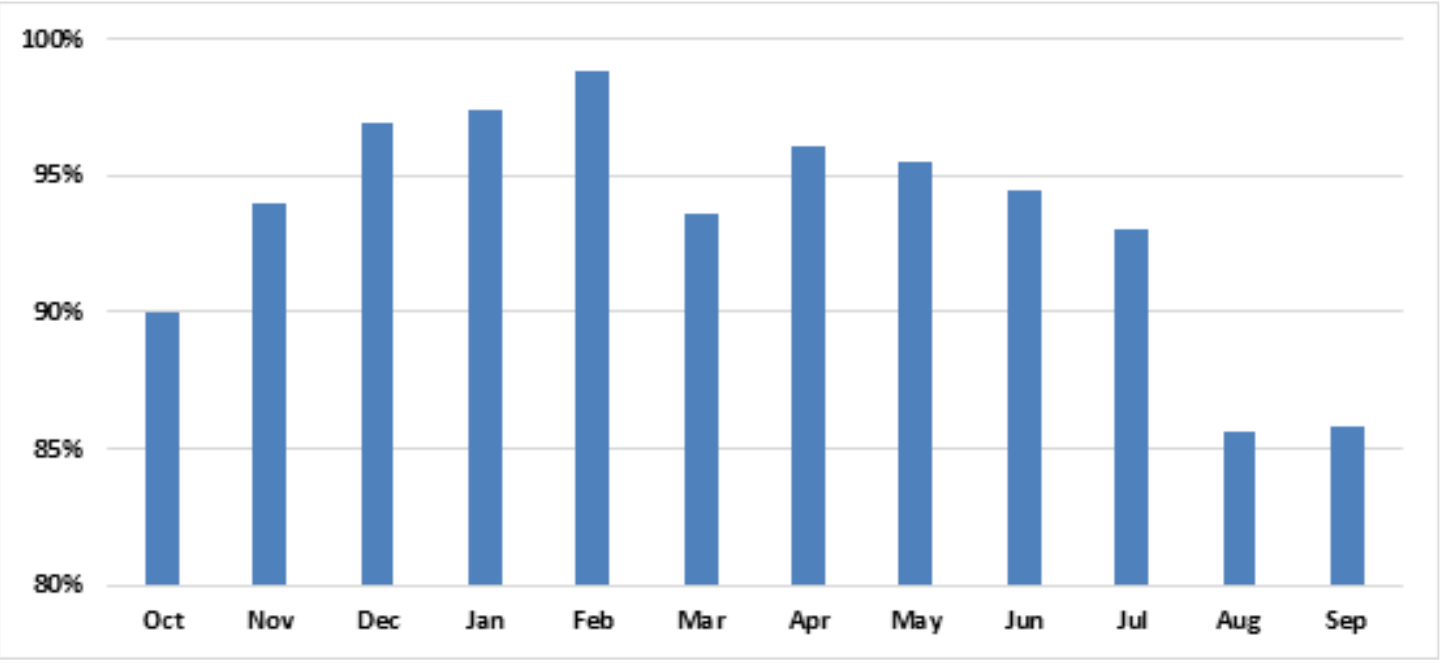

Figure 7. Environmental flow reliability per month, assuming $K^{*}=0$.

In the case of water demand for human needs, assuming a larger reservoir $\left(\mathrm{K}^{*}=0\right)$ and the worst-case scenario demand profile, decent performance is observed throughout traditionally wet months in a hydrological year (October through April), yet very poor results are given during the dry months of June, July, and August where reliability drops below $10 \%$. This is a consequence of two things: Naturally the demand is highest during these months, but also this particular inflow profile is marked by huge drought periods in a typical year, most often occurring during dry months, and lasting up to seven months with zero inflows. To meet demand under these extreme conditions, only a very large reservoir can achieve satisfactory results.

On the other hand, the environmental flow reliability is much more stable regardless of month. Assuming a larger reservoir $\left(\mathrm{K}^{*}=0\right)$, generally values above $90 \%$ are achieved, with a slight dip during August and September. This dip can be attributed to the naturally low inflow values and frequent dry spells during those months.

\section{Discussion}

After running the model on the case study of Lesotho and studying its results, there are elements that promote further discussion, as well as aspects that require more research if it is 
to be applied in different locations and/or real case studies. These points are briefly outlined below.

- This stochastic eco-hydrological model is meant to be a simple benchmark for desktop studies. Its aim is to present a parsimonious method to estimate the optimal reservoir size for a given river catchment with known streamflow and demand profiles. In order to truly assess its efficiency and accuracy, one must conduct an evaluation of the model in real world conditions, preferably in an entirely different location. This would allow testing against all of the model's assumptions and constraints.

- Naturally, the above is no simple task; while the framework presented in this study is easy to use, the inputs required can prove very difficult to obtain. First off, at least twenty years of monthly inflow data are required to implement a stochastic algorithm and generate a synthetic timeseries with scientifically reasonable levels of accuracy. Next, a full EFA must be conducted in the case study area. If a holistic methodology in line with current field standards is applied, this entails a network of at least two to three years of measurements. Depending on the site, this data may not be readily available or be substantially lacking in quality $[11,42,44]$.

- Further to the above point, it is important to also conduct habitat retention analysis in the given study area the framework is tested in. Not only is this a mandatory requirement for modern holistic EFAs, it also results in dynamic flow that oftentimes requiring less water overall [11,28].

- Once environmental flow data is available, a dynamic profile needs to then be set up in conjunction with the model proposed in this study. Currently, the framework simply assumes a normal random value between minimum and maximum baseflows. This leads to cases of unnaturally low environmental flow values during some traditionally wet months and vice versa. While this is a good enough approximation for determining a reservoir size given the factor of numbers involved, it would be better to implement a "smart" distribution of environmental flow demand using a secondary algorithm. For example, this could be a demand distribution that would adapt how close it is to the minimum or maximum baseflow values depending on how wet the last few months were. Furthermore, simulated droughts or floods could also be accommodated in this way, as is often requested by modern EFAs. Adding this parametric capability to environmental flow will allow researchers to further stress test their reservoirs against even stricter criteria for the ecosystem.

- In a similar vein, the nature of human water demand may vary significantly between different parts of the globe. The demand profile from this study assumed that mean annual inflow is the maximum monthly demand. While this conservative estimate is a good enough approximation for the needs of this study, in order to conduct a proper evaluation of the model in a real-world scenario, a historical timeseries of human water demand would also be necessary [38,39,42]. Using actual data from a source such as a public water utility or local authority, one could generate a monthly schedule of water demand much closer to actual conditions.

- In its present state, the model's criteria for environmental flow categorize any month where demands were not met as a failure. While this is true for reliability as a definition, this doesn't necessarily directly correlate with a failure of protecting the ecosystem. While for the case study of Lesotho, which is a predominantly dry region in direct need of water, this analogy is likely apt, there are multiple catchments around the world where droughts can be beneficial. It is necessary, then, to be able to distinguish under which cases failure to meet environmental flow demands is detrimental to the ecosystem of a given area. If there are no significant links between the two, the concept of reliability may not be sufficient to adequately explain the nature of a catchment $[18,19,40]$. 


\section{Conclusions}

As with any engineering project, dam design is a science inherently linked with risk and uncertainty. The aspect of reservoir sizing is one that is often the center of debate between stakeholders, as it directly governs the scale of works, and thus the subsequent environmental impacts. As the newer holistic EFA approaches suggest, there usually more than one adequate solution to the problem of setting up an environmental flow scheme downstream of a dam. Which one ends up being chosen raises questions of trust between the operator and the public. Nowadays, presenting a sustainable design that prioritizes the ecosystem can serve as a way of bridging the gap between these groups with conflicting interests, and this is where the stochastic eco-hydrological framework presented in this study can come into play.

In this work, it has been made clear that maintaining and prioritizing an eco-friendly flow regime for any given reservoir, without significant costs in meeting other needs is a feasible goal no matter the reservoir size. Expanding from this point, satisfying both environmental and human water demands appears to be more reliant on reservoir capacity than even the demand profiles themselves. This suits engineers from a design perspective, as by adopting this proposed framework, they may quantify exactly how cost-efficient their proposed reservoir will be, by linking its size to reliability for both ecosystem and local demand.

The results of the stochastic eco-hydrological framework appear to indicate that the larger the reservoir, the more efficient it is, both for meeting local demand and maintaining a dynamic natural river flow downstream. However, large dam projects are often seen as extremely invasive and hazardous to the environment. It is important that the importance of large reservoirs from an engineering and hydrological perspective is recognized, but also every design is linked to risk. This risk can never be eliminated, but it can be quantified, and steps can be taken to mitigate potential losses. These losses are not only comprised of the initial landscaping works required to build a dam; their impact is an on-going process that continues well after the structure's life expectancy. As such, it is a dam engineer's duty to ensure sustainability for their works overall. The model proposed in this study combines the concepts of engineering, stochastics, and environment into hydrology, with the aim of helping designers achieve this goal. While it may not present a final solution, it can definitely highlight the importance and simplicity of preserving environmental flow in modern dam operation schemes.

Author Contributions: Conceptualization, A.K., P.T. and A.T.; methodology, A.T.; validation, A.K., A.T. and P.T.; formal analysis, A.K.; investigation, A.K.; resources, P.T.; data curation, A.T; writing-original draft preparation, A.K.; writing - review and editing, P.T.; visualization, A.T.; supervision, P.T.

Funding: This research received no external funding;

Conflicts of Interest: The authors declare no conflict of interest.

\section{References}

1. Montanari, A.; Young, G.; Savenije, H.H.G.; Hughes, D.; Wagener, T.; Ren, L.L.; Koutsoyiannis, D.; Cudennec, C.; Toth, E.; Grimaldi, S.; et al. "Panta Rhei-Everything Flows": Change in hydrology and society - The IAHS Scientific Decade 2013-2022. Hydrol. Sci. J. 2013, 58, 1256-1275.

2. Shumilova, O.; Tockner, K.; Thieme, M.; Koska, A.; Zarfl, C. Global Water Transfer Megaprojects: A Potential Solution for the Water-Food-Energy Nexus? Front. Environ. Sci. 2018, 6, 150.

3. Sargentis, G.-F.; Ioannidis, R.; Karakatsanis, G.; Sigourou, S.; Lagaros, N.D.; Koutsoyiannis, D. The Development of the Athens Water Supply System and Inferences for Optimizing the Scale of Water Infrastructures. Sustainability 2019, 11, 2657.

4. Mays, L.W. A very brief history of hydraulic technology during antiquity. Environ. Fluid Mech. 2008, 8, 471-484.

5. Koutsoyiannis, D.; Mamassi, N.; Tegos, A. Logical and illogical exegeses of hydrometeorological phenomena in ancient Greece. Water Sci. Technol. Water Supply 2007, 7, 13-22. 
6. King, J.; Brown, C.; Sabet, H. A scenario-based holistic approach to environmental flow assessments for rivers. River Res. Appl. 2003, 19, 619-639.

7. Tyralis, H.; Tegos, A.; Delichatsiou, A.; Mamassis, N.; Koutsoyiannis, D. A Perpetually Interrupted Interbasin Water Transfer as a Modern Greek Drama: Assessing the Acheloos to Pinios Interbasin Water Transfer in the Context of Integrated Water Resources Management. 2017, 18.

8. Koutsoyiannis, D. Reconciling hydrology with engineering. Hydrol. Res. 2014, 45, 2-22.

9. FEARNSIDE, P.M. Environmental Impacts of Brazil's Tucuruí Dam: Unlearned Lessons for Hydroelectric Development in Amazonia. Environ. Manage. 2001, 27, 377-396.

10. Dudgeon, D.; Arthington, A.H.; Gessner, M.O.; Kawabata, Z.-I.; Knowler, D.J.; Lévêque, C.; Naiman, R.J.; Prieur-Richard, A.-H.; Soto, D.; Stiassny, M.L.J.; et al. Freshwater biodiversity: importance, threats, status and conservation challenges. Biol. Rev. 2006, 81, 163.

11. Tegos, M.; Nalbantis, I.; Tegos, A. Environmental flow assessment through integrated approaches. Eur. Water 2017, 60, 167-173.

12. Dunbar, M.J.; Gustard, A.; Acreman, M.C. Review of Overseas Approaches to Setting River Flow Objectives.; Institute of Hydrology: Wallingford, UK, 1998;

13. Mishra, A.K.; Singh, V.P. A review of drought concepts. J. Hydrol. 2010, 391, 202-216.

14. King, J.; Tharme, R.E.; Brown, C. Definition and Implementation of Instream Flows.; Cape Town, 1999.

15. Holmgren, M.; Gómez-Aparicio, L.; Quero, J.L.; Valladares, F. Non-linear effects of drought under shade: reconciling physiological and ecological models in plant communities. Oecologia 2012, 169, 293-305.

16. Efstratiadis, A.; Tegos, A.; Varveris, A.; Koutsoyiannis, D. Assessment of environmental flows under limited data availability: case study of the Acheloos River, Greece. Hydrol. Sci. J. 2014, 59, 731-750.

17. Arthington, A.H.; Rall, J.L.; Kennard, M.J.; Pusey, B.J. Environmental flow requirements of fish in Lesotho rivers using the DRIFT methodology. River Res. Appl. 2003, 19, 641-666.

18. Dotson, J.D. Describe a Balanced Ecosystem Available online: https://sciencing.com/describebalanced-ecosystem-5761235.html (accessed on Oct 9, 2019).

19. Tharme, R.E. A global perspective on environmental flow assessment: emerging trends in the development and application of environmental flow methodologies for rivers. River Res. Appl. 2003, 19, 397-441.

20. Seesholtz, A.; Cavallo, B.J.; Kindopp, J.; Kurth, R. Juvenile Fishes of the Lower Feather River: Distribution, Emigration Patterns, and Associations with Environmental Variables. 27.

21. Singer, M.B. The influence of major dams on hydrology through the drainage network of the Sacramento River basin, California. River Res. Appl. 2007, 23, 55-72.

22. Xu, Y.; Zhang, L.; Jia, J. Lessons from catastrophic dam failures in August 1975 in Zhumadian, China. In Proceedings of the Geosustainability and geohazard mitigation; 2008; pp. 162-169.

23. Arthington, A.H.; Bunn, S.E.; Poff, N.L.; Naiman, R.J. The Challenge of Providing Environmental Flow Rules to Sustain River Ecosystems. Ecol. Appl. 2006, 16, 1311-1318.

24. Poff, N.L.; Richter, B.D.; Arthington, A.H.; Bunn, S.E.; Naiman, R.J.; Kendy, E.; Acreman, M.; Apse, C.; Bledsoe, B.P.; Freeman, M.C.; et al. The ecological limits of hydrologic alteration (ELOHA): a new framework for developing regional environmental flow standards. Freshw. Biol. 2010, 55, 147170 .

25. Acreman, M.C.; Dunbar, M.J. Defining environmental river flow requirements: a review. Hydrol. Earth Syst. Sci. Discuss. 2004, 8, 861-876.

26. Commission of the European Communities (CEC) Directive 2000/60/EC of the European Parliament and of the Council of 23 October 2000 establishing a framework for Community action in the field of water policy Available online: https://eur-lex.europa.eu/legalcontent/en/TXT/?uri=CELEX:32000L0060 (accessed on Nov 9, 2019).

27. Acreman, M.; Aldrick, J.; Binnie, C.; Black, A.; Cowx, I.; Dawson, H.; Dunbar, M.; Extence, C.; Hannaford, J.; Harby, A.; et al. Environmental flows from dams; the Water Framework Directive. Proc. ICE - Eng. Sustain. 2009, 162, 13-22.

28. Tegos, A.; Schlüter, W.; Gibbons, N.; Katselis, Y.; Efstratiadis, A. Assessment of Environmental Flows from Complexity to Parsimony - Lessons from Lesotho. Water 2018, 10, 1293.

29. Arthington, A.H.; Pusey, B.J. In-stream flow management in Australia: methods, deficiencies and future directions. Aust. Biol. 1993, 6, 52-60. 
30. King, J.; Louw, D. Instream flow assessments for regulated rivers in South Africa using the Building Block Methodology. Aquat. Ecosyst. Health Manag. 1998, 1, 109-124.

31. Brown, J. IMPROVING ENVIRONMENTAL FLOW METHODS USED IN CALIFORNIA FERC LICENSING. 241.

32. Project Overview Available online: https://web.archive.org/web/20080511013231/http://www.lhwp.org.ls/overview/Default.htm (accessed on Oct 8, 2019).

33. Sene, K.J.; Jones, D.A.; Meigh, J.R.; Farquharson, F.A.K. Rainfall and Flow Variations in the Lesotho Highlands. Int. J. Climatol. 1998, 18, 329-345.

34. Climate of Lesotho Available online: https://web.archive.org/web/20071224101153/http://www.lesmet.org.ls/climate_of_lesotho.htm (accessed on Oct 8, 2019).

35. King, J.M.; Tharme, R.E. Assessment of the Instream Flow Incremental Methodology and Initial Development of Alternative Instream Flow Methodologies for South Africa; Water Research Commission: Pretoria, South Africa, 1994;

36. Box, G.E.P.; Jenkins, G.M.; Reinsel, G.C.; Ljung, G.M. Time Series Analysis: Forecasting and Control, 5th Edition I Wiley; 2015; ISBN 978-1-118-67502-1.

37. Koutsoyiannis, D. A generalized mathematical framework for stochastic simulation and forecast of hydrologic time series. Water Resour. Res. 2000, 36, 1519-1533.

38. Koutsoyiannis, D. Reliability Concepts in Reservoir Design Available online: https://www.researchgate.net/publication/229676115_Reliability_Concepts_in_Reservoir_Design? enrichId=rgreq-2532ce9d28e863afe2697199c6b2738b-

XXX\&enrichSource=Y292ZXJQYWdlOzIyOTY3NjExNTtBUzoyMDcxNjUzMTU5MTU3ODBAMT QyNjQwMzQ2ODU5MA\%3D\%3D\&el=1_x_2\&_esc=publicationCoverPdf (accessed on Jul 9, 2019).

39. Tsoukalas, I.; Makropoulos, C.; Koutsoyiannis, D. Simulation of Stochastic Processes Exhibiting Any-Range Dependence and Arbitrary Marginal Distributions. Water Resour. Res. 2018, 54, 9484 9513.

40. Dimitriadis, P.; Koutsoyiannis, D. Stochastic synthesis approximating any process dependence and distribution. Stoch. Environ. Res. Risk Assess. 2018, 32, 1493-1515.

41. Venediki, A.; Giannoulis, S.; Ioannou, C.; Malatesta, L.; Theodoropoulos, G.; Tsekouras, G.; Dialynas, Y.; Papalexiou, S.M.; Efstratiadis, A.; Koutsoyiannis, D. The Castalia stochastic generator and its applications to multivariate disaggregation of hydro-meteorological processes.; 2013; p. 11542.

42. Zacharopoulou, E.; Tsoukalas, I.; Efstratiadis, A.; Koutsoyiannis, D. Impact of sample uncertainty of inflows to stochastic simulation of reservoirs. In Proceedings of the European Geosciences Union General Assembly 2019; EGU, 2019.

43. Wilhite, D.A.; Glantz, M.H. Understanding: the Drought Phenomenon: The Role of Definitions. Water Int. 1985, 10, 111-120.

44. Efstratiadis, A.; Tegos, A.; Varveris, A.; Koutsoyiannis, D. Assessment of environmental flows under limited data availability: case study of the Acheloos River, Greece. Hydrol. Sci. J. 2014, 59, 731-750.

45. Fourniotis, N.T. A Proposal for Impact Evaluation of the Diversion of the Acheloos River, on the Acheloos Estuary in Western Greece. Int. J. Eng. Sci. Technol. 2012, 4, 10.

46. Koutsoyiannis, D. Scale of water resources development and sustainability: small is beautiful, large is great. Hydrol. Sci. J. 2011, 56, 553-575. 